\title{
"Qual destas moças é você?"” o autoconhecimento produzido pelos testes da imprensa feminina
}

\author{
"Which one of these girls are you?" Self-knowledge produced by \\ female press tests
}

\section{Constantina Xavier Filha ${ }^{2}$}

\section{RESUMO}

Este texto pretende refletir acerca dos discursos veiculados e produzidos por um elemento textual peculiar da imprensa feminina: os testes. O estudo fundamenta-se nos pressupostos de gênero e de alguns conceitos dos estudos foucaultianos. Pretende discutir os enunciados expressos na imprensa (revistas Capricho e Cláudia) com a temática da feminilidade e da sexualidade nas primeiras décadas da segunda metade do século XX. Os testes, mediante enunciados prescritivos e normalizadores, revelaram ser instrumentos de dispositivos pedagógicos com o objetivo de "conduzir as condutas" femininas, uma vez que se tornam capazes de provocar o exame e a confissão, tornando o discurso da intimidade visível e verbalizado. Indicam conceitos de "verdade", apoiados em códigos morais e, especialmente, em preceitos fundamentados em teorias científicas a respeito da conduta feminina. O conceito de verdade está ligado a sistemas de poder, que apontam para regimes não necessariamente negativos ou repressivos,

\footnotetext{
1 Título do teste publicado na revista Capricho (n. 82, 1958).

2 Doutora em Educação pela FEUSP. Professora do Programa de Pós-Graduação em Educação da Universidade Federal de Mato Grosso do Sul (UFMS). tinaxav@gmail.com.
} 
mas, fundamentalmente, produtivos, porque incitam à reflexão e propiciam possibilidades de trabalho pessoal.

Palavras-chave: Imprensa Feminina; Sexualidade; Gênero

\begin{abstract}
This paper aims to make a reflection on the discourses conveyed and produced by a peculiar textual element in the female press: tests. The study is based on gender assumptions and some foucaultian concepts. It intends to discuss statements found in the press (magazines Capricho and Cláudia) regarding female themes and sexuality in the first decades of the second half of the $20^{\text {th }}$ century. By using prescriptive and normalizing statements, the tests were revealed to act as pedagogical tools whose objective was "to guide female conduct", as they were able to prompt examination and confession, thus making it possible for the inner discourse to be visible and verbalized. The tests indicate concepts of "truth" supported by moral codes and, especially, by precepts based on scientific theories about female conduct. The concept of truth is connected to power systems, pointing to regimes that are not necessarily negative or repressive, but fundamentally productive, as they stimulate reflection and provide personal work possibilities.
\end{abstract}

Keywords: Female Press; Sexuality; Gender

\title{
FONTES SELECIONADAS
}

Este texto ${ }^{3}$ parte de pesquisa ${ }^{4}$ mais ampla. Pretende refletir acerca dos discursos veiculados e produzidos por um setor peculiar da imprensa feminina: os testes. O estudo fundamenta-se nos pressupostos de gênero e de alguns conceitos dos estudos foucaultianos. Pretende discutir os enunciados expressos na imprensa feminina brasileira com a temática da feminilidade e da sexualidade feminina nas três primeiras décadas da segunda metade do século XX; período fértil, visto que a sexualidade 
feminina e a constituição dos sujeitos de diversas identidades - tais como a sexual e a de gênero - passaram a ser objeto de ciências e de movimentos sociais, produzindo, nos últimos anos, nas sociedades ocidentais, múltiplos enunciados. Os movimentos de contestação social, como o feminista, o de gays e de lésbicas, levantaram questões e, conseqüentemente, novas visões dos direitos sexuais, além do entendimento do conceito de gênero como fruto de questões sociohistóricas e culturais. A pílula anticoncepcional permitiu a vivência da sexualidade feminina com mais prazer, desvinculando a prática do sexo da reprodução. A Sexologia Moderna passou a ditar novos procedimentos para a mulher sobre como se relacionar com o corpo e se conduzir sexualmente. Essas "urgências históricas", tal como as designa Foucault (1996), contribuíram para a ressignificação do dispositivo ${ }^{5}$ da sexualidade nas últimas décadas.

A fonte privilegiada foi a imprensa feminina, mais especificamente os textos das revistas brasileiras Capricho e Cláudia. A revista Capricho, publicada pela Editora Abril, em São Paulo, foi lançada em 18 de junho de 1952, com periodicidade quinzenal, e é considerada por Dulcília Buitoni (1981) como responsável pelo início da nossa grande imprensa feminina no Brasil. Várias características comprovam essa constatação, como o crescente número de exemplares: do primeiro número, de cerca de 26 mil, ultrapassa os 100 mil já no seu número 9 (quando passa a ter

3 Este texto apresenta algumas mudanças do original que foi apresentado no GT 23 "Gênero, Sexualidade e Educação", durante a 29a Reunião Anual da ANPEd, outubro/2006.

4 Pesquisa de doutorado - com bolsa da Capes/PICDT - orientada pela professora Dra. Denice Barbara Catani (FEUSP) e co-orientada pelo professor Dr. Jorge do Ó (Universidade de Lisboa).

5 Por dispositivo entende-se "um conjunto decididamente heterogêneo que engloba discursos, instituições, organizações arquitetônicas, decisões regulamentares, leis, medidas administrativas, enunciados científicos, proposições filosóficas, morais, filantrópicas. Em suma, o dito e o não dito são os elementos do dispositivo. O dispositivo é a rede que se pode estabelecer entre estes elementos" (FOUCAULT, 1996, p. 244). 
periodicidade mensal). Um ano após, atinge 240 mil exemplares; em outubro de 1957, conta com 360 mil exemplares, e esse número cresce para mais de 500 mil no final da década de 1950. O número de páginas também é revelador de sua amplitude: passa de uma pequena revista com formato de gibi $(14 \times 19 \mathrm{~cm})$, com número médio de 35 páginas nos seus primeiros números, em tiragem quinzenal, para tamanhos maiores $(19 \mathrm{x}$ $27 \mathrm{~cm}$ ), com mais de 100 páginas no final da década. Dentre as características da revista, a inovação é a veiculação de episódios completos de fotonovelas em cada edição, além de textos relacionadas à psicologia, moda e comportamento feminino.

A revista, nos primeiros números, trazia em suas capas a designação "revista quinzenal feminina", depois passou a ser "revista mensal da Juventude Moderna" e, logo no número 25, em março de 1954, a "revista da mulher moderna". Tais designações são importantes para expressar o perfil das leitoras, ou seja, o feminino, mais especificamente a moça jovem da classe média, consumidora em potencial, alfabetizada, solteira, e, além dela, a jovem mulher recém-casada.

A revista Cláudia tem seu primeiro número em outubro de 1961, também pela Editora Abril, em São Paulo. Segundo o fundador da editora, Victor Civita, em entrevista a Dulcília Buitoni (apud Santos, 1996), essa revista tinha certa filosofia editorial norte-americana, embora usasse material italiano. As primeiras edições, com medidas de $26 \times 33 \mathrm{~cm}$, mudam de diagramação e tamanho durante as décadas de 1960 e 1970, para 22 × $30 \mathrm{~cm}$, diminuindo de tamanho e aproximando-se do atual. No início da década de 1960, a revista continha cerca de 102 páginas; passou para 186, para 212 e, no final dessa década, para 276 páginas. No início da década de 1980, a tiragem era de 400 mil exemplares.

Um dos diferenciais da revista diz respeito ao seu próprio nome, ou seja, tem nome de uma mulher, que seria escolhido pelo diretor da editora e pela sua esposa, Sylvana Civita, se viessem a ter uma filha. A tendência 
em dar às revistas femininas nomes próprios era comum nessa época na França. "Cláudia, com nome de gente, veio ao encontro de uma certa busca de identidade da mulher da classe média urbana; também veio estimular e ser estimulada por todo um consumo emergente. [...] inaugurou um novo estilo de editar moda, beleza, culinária e decoração" (Buitoni, 1986, p. 49). Ainda segundo essa autora, a revista Cláudia, desde o seu início, procurou adequar-se às exigências do mercado e também às regras morais da sociedade da época.

O público leitor da revista Cláudia, no período estudado, é a mulher jovem, de classe média, consumidora em potencial, alfabetizada, casada, com ou sem filhas e filhos. Apesar dessa delimitação do público-alvo, nas décadas analisadas, aparecem indicações de outros perfis de leitoras, sem deixar, contudo, de ser a mulher, que poderia ser mais velha e quase sempre casada e com filhas/os. Para exemplificar a maior amplitude do universo de possíveis leitoras e leitores, há sinais, a partir dos textos, artigos e reportagens, de que, na década de 1960, a revista também era indicada para a moça, jovem e solteira, a dona-de-casa e a senhora em época da menopausa. Apesar das nuances salientadas, a revista é destinada explicitamente ao público feminino, havendo, no entanto, algumas indicações de que também se destinavam aos homens, especialmente aos companheiros das leitoras.

As revistas ${ }^{6}$ selecionadas foram consultadas página por página, para, posteriormente, selecionar-se o que seria pertinente ao objeto estudado. Foram coletados textos, artigos, reportagens, cartas, testes. Os textos apresentavam características em comum a destacar: conceitos das diversas ciências que se apontam como referência de "verdade" sobre a conduta feminina; enunciados com o objetivo de normalizar as condutas; sugestões e indicações à leitora sobre como ser capaz de produzir subjetividades; ideal de feminilidade e vivência da sexualidade para mulheres no Brasil. 
Para a análise que se pretende neste artigo, foram selecionados 59 testes publicados nas duas revistas: 28 da revista Capricho (1952-1960) e 31 da Cláudia $\left(1961-1971^{7}\right)$. Os testes mostraram ser instrumentos férteis ao veicular e produzir um tipo de discurso de saber-poder que privilegia um determinado modo de ser mulher e de ser mulher sexuada no período investigado.

\section{“QUAL DESTAS MOÇAS É VOCÊ?” \\ - O EXAME E A CONFISSÃO COMO ESTRATÉGIAS DE PRODUÇÃO DE SUBJETIVIDADE}

Os testes são constituídos de enunciados que instigam a reflexão, ou seja, um tipo de exame e, também, de confissão, na medida em que a mulher é induzida a produzir discursos sobre si própria a partir das categorias questionadas e normalizadas por aqueles instrumentos. Além de estimular o trabalho pessoal de quem se habilita a participar desse jogo, os testes expressam discursos de saber e poder sobre conceitos quase sempre fundamentados nas ciências $p s i^{8}$, favorecendo a normalização de condutas.

O exame, segundo Foucault (1977), é uma "técnica delicada" comprometida com um campo de saber e de poder, especialmente nos últimos três séculos. É através dele, ou de suas ritualizações, que foi possível dar visibilidade ao sujeito. Essa individualidade, porém, é analisada sob "rótulos" que acabam por objetivar os indivíduos. O referido autor estuda os códigos da individualidade disciplinar que permitiram registrar ou descrever, homogeneizar e catalogar as pessoas por meio do aparelho da escrita que acompanhou os exames ao longo dos

$6 \mathrm{Na}$ pesquisa de doutorado, também se privilegiou a análise de uma revista feminina portuguesa Modas \& Bordados. As revistas foram selecionadas a partir de narrativas de histórias de vida de mulheres-professoras brasileiras e portuguesas. Ver: XAVIER FILHA (2005).

7 Do período posterior ao ano de 1971, selecionou-se apenas um teste sobre a temática estudada: "Você é uma dona de casa feliz?" (Cláudia, n. 203, 1978). 
séculos. O processo de descrever o sujeito, fazendo dele um "caso", torna-o objeto. O indivíduo é "descrito, mensurado, medido, comparado a outros e isso em sua própria individualidade" (Foucault, 1977, p. 170). Tal processo, diferentemente do que possa parecer, não representa um poder autoritário; ao contrário, “à medida que o poder se torna mais anônimo e mais funcional, aqueles sobre os quais se exerce tendem a ser mais fortemente individualizados" (Foucault, 1977, p. 171). O exame, especialmente o realizado pelas ciências, também pode ser pensado como estratégia de dispositivos pedagógicos que o próprio sujeito realiza sobre si mesmo, questionando-se, refletindo. Os testes, aqui analisados, serão observados como uma dessas técnicas de saber-poder que instigam o sujeito a fazer um trabalho sobre si mesmo, refletindo e produzindo discursos sobre si e, com isso, constituindo subjetividades.

Os testes, objeto desta análise, foram agrupados em duas categorias: a primeira, a das condutas femininas; a segunda, a do autoconhecimento pessoal e amoroso da mulher. As duas categorias indicam o que se considerava ideal para a vivência da mulher no período de 1950 a 1971, seja na conduta cotidiana, seja na possibilidade de relacionamento com o parceiro, induzindo as leitoras, sobretudo, ao autoconhecimento. Ambas as categorias trazem, em seu âmbito, quase sempre de forma explícita, textos ou enunciados expressos na resolução dos testes, ressaltando o que se pretende como ideal para a vivência da mulher no período citado. Apesar das diferentes finalidades dos testes, o autoconhecimento feminino é o objetivo a ser alcançado, pois, enfatizado seu papel educativo, era preciso levar a mulher a refletir sobre suas condutas para induzi-la a mudar comportamentos.

\footnotetext{
8 Na revista Capricho, os testes, em sua maioria, são publicados na seção "Psicologia", assinados por psicólogos/as.
} 
Os testes designados como pertencentes à primeira categoria, "condutas femininas", serão descritos a seguir. Seus objetivos evidenciavam a formação de condutas ditas femininas. Apesar de sofrerem mudanças ao longo das décadas analisadas, o que eles expressam é a idéia de que as pessoas se autoconheçam, e, para isso, se auto-analisem constantemente, mudando de comportamento. Trata-se, pois, de um trabalho interno de busca da perfeição. Tal intento é evidente nos enunciados, que utilizam termos das ciências, base que lhes daria legitimidade social. As condutas esperadas das mulheres a que se referem são a da boa esposa, da boa dona-de-casa, da boa mãe. Para isso ressaltam: a preparação ao casamento; a eterna vigilância na conquista do noivo e, depois, do marido; a vivência no casamento; o desempenho na lida cotidiana do lar; a maternidade. A demarcação dessas condutas aparece, especialmente, na década de 1950; mas esses conceitos continuam nas décadas posteriores, embora com outros enunciados.

Vejamos alguns dos títulos que comprovam as condutas esperadas:

Revista Capricho: "Casar-me-ei logo?” (n. 5, 1952); "Serei boa dona de casa?” (n. 25, 1954); “Estou apta para o casamento?” (n. 68, 1957); “Já que estamos noivos... casemo-nos!" (n. 98, 1960); "Será você uma boa espôsa?” (n. 99, 1960).

Revista Cláudia: "Você é uma companheira ideal?" (n. 5, 1962); "Você é boa mãe?" (n. 14, 1962); "Você é boa esposa?" (n. 15, 1962); "Você está pronta para o casamento?" (n. 64, 1967); "Você é uma dona de casa feliz?" (n. 203, 1978).

Os títulos são escritos em forma de questionamento, visando à reflexão direta da leitora, antes até do preenchimento das questões. Esses títulos refletem o teor dos testes que têm como objetivo instigar a autoreflexão feminina acerca do que é considerado ideal para a mulher que pretende se casar ou para a que já atingiu esse objetivo e necessita garantir o êxito matrimonial e a vivência da maternidade. 
Dois testes sobre avaliação da mulher acerca da capacidade para o matrimônio merecem destaque. O primeiro, publicado em abril de 1960, na revista Capricho (n. 98), é representativo de vários outros publicados na mesma revista. Sua marca característica é a apresentação de um texto explicativo que precede os questionamentos. O título é convidativo: "Já que estamos noivos... casemo-nos!", incentivando o casamento logo após o período preparatório do noivado. $O$ texto começa revestido de autoridade ao afirmar que "este artigo ensina a resolver problemas sentimentais, evitando graves desilusões". Em seguida, expõe o caso de uma jovem, angustiada pela pressão de seu noivo que lhe pedia uma "prova de amor". Tal situação, segundo o artigo, teria sido vivenciada por muitas jovens que se calavam e permaneciam numa angustiante dúvida. No primeiro parágrafo aparece o seguinte veredicto:

\begin{abstract}
Muitas garotas estão no mesmo caso e sofrem em silêncio, não sabendo que atitude tomar e sem coragem de pedir conselho às suas mães. Pois bem: em casos desta natureza, não há motivos para dúvida ou perplexidade. A resposta é uma só e muito simples: nada de "provas de amor" antes do casamento.
\end{abstract}

A justificativa para que a noiva não ceda é apresentada logo em seguida:

\footnotetext{
Em noventa por cento dos casos, os chamados "casamentos de experiência" naufragam miseravelmente. Pondo de parte qualquer consideração de ordem moral ou religiosa, nosso ponto de vista é confirmado por uma série de estatísticas, que, com a eloqüente linguagem das cifras, demonstraram que são muito mais felizes no casamento os casais que não tiveram muita intimidade durante o noivado.
} 
O conceito de verdade repassado no texto apóia-se em indicativos estatísticos para reforçar o argumento. A felicidade no casamento é posta em jogo para convencer a mulher a manter-se casta; caso contrário, verá ruir seu "maravilhoso castelo de sonhos", e, pior, "relações dessa natureza, transformam-se automaticamente, na consciência da moça, em relações ilícitas e provocam um sentimento de culpa que produz ansiedade e angústia”, salienta o teste.

Além desse inevitável fim para o dilema da moça, o texto ainda insiste em questioná-la: "E quem poderá assegurar à vítima dessa chantagem, que 'êle', satisfeito seu desejo, não passe, tempos depois, a uma nova aventura, deixando a pobre garôta chorar amargamente pelo erro cometido?". Ou ainda: "Depois da posse, continuará a estimá-la, ou pensará que, como foi para êle, ela seria também uma conquista fácil para qualquer outro?”. Na melhor hipótese, havendo o matrimônio após a prática sexual, em muitos casos, "acontece que a felicidade conjugal é obscurecida por esse êrro passado, cuja culpa o marido atribui à esposa".

A culpa é um dos elementos do dispositivo pedagógico dos testes veiculados pela imprensa feminina. Produz-se um discurso em que se reprova o prazer momentâneo do ato sexual e, com isso, garanta a virgindade como condição de felicidade conjugal. É importante registrar que, nesse texto, não se fala abertamente do ato sexual antes do casamento. O termo "prova de amor", por exemplo, sugere essa prática. Explicitamente, entretanto, o ato sexual fora do casamento é considerado um "erro" que inevitavelmente causará culpa e comprometerá a felicidade conjugal. Além desse conceito de "verdade", que imprime ao texto uma relação de autoridade, há os exemplos extraídos da realidade e, especialmente, do discurso considerado verdadeiro, o científico.

Em seguida a toda a discussão em torno da manutenção da virgindade, propõem-se quinze questões a serem respondidas pelas mulheres e, também, por eles, os noivos. O dispositivo pedagógico da 
revista torna-se ousado e eficiente, pois leva o público - feminino e masculino - a se examinar em relação ao tema abordado para que um e outro saibam de seus posicionamentos e, especialmente, passem a ter pontos de vista convergentes.

Eis algumas questões sugeridas para "ela":

Acha que êle tem certeza que a ama? le dá o devido valor aos trabalhos caseiros? Reconhece que você tem o direito de ter seus segredinhos? le consegue, sem esfôrço, ser tolerante e afetuoso para com as crianças? Estima-a a ponto de renunciar a uma "prova de amor" antes do casamento?

"Êle" é questionado, dentre outras questões, a respeito das seguintes:

Sua noiva quer ter sua própria casa e filhos? Tem certeza que, no novo lar que você vai oferecer-lhe, ela não chorará a falta da casa de seus pais? Ela concordará em renunciar, sem esfôrço, a um presente que você lhe tenha prometido, se suas condições econômicas assim o exigirem? Ela é feliz ao seu lado, mesmo que você não lhe ofereça diversões como cinema, bailes e passeios? Não o censura se, uma vez ou outra, você deixa de ir vê-la para passar algumas horas em companhia de amigos? Estaria disposta a trabalhar depois de casada, para ajudar a manter a família? Tem certeza que ela sabe preparar uma boa refeição ou consertar uma roupa? Se houve um êrro em seu passado, tem certeza que, apesar disso, ela é uma mulher digna e respeitável?

Tanto para os homens quanto para as mulheres, sugerem-se perguntas que instigam ao conhecimento da parceira ou do parceiro; especialmente, em relação às condutas consideradas perfeitas para um marido ou uma esposa ideal. Do homem, espera-se que seja o provedor, muito embora possa contar com a "ajuda" financeira da mulher. Também 
se espera que ele goste de crianças, que respeite os pequenos/grandes segredos da esposa, que goste dos familiares dela, que seja capaz de renunciar a uma "prova de amor" e continuar a estimar a noiva. Dela, por sua vez, espera-se que compreenda o marido até mesmo nos momentos em que ele passa junto aos amigos, que tolere seus defeitos, que saiba cuidar do lar, cozinhar e consertar roupa, demonstrando felicidade, mesmo quando ele não lhe possa propiciar diversões como cinema, bailes ou passeios. E, fundamentalmente, que ela seja "digna e respeitável", mesmo que tenha cometido algum "erro" no passado. Insinua-se que esse deslize é de caráter sexual, mesmo que seja com o próprio noivo. Tais questões são consideradas fundamentais para a "futura felicidade conjugal", da qual um dos pilares é a manutenção da virgindade até o casamento.

Após o texto inicial, as questões do teste propriamente dito e a conclusão através da pontuação, há uma síntese para reafirmar os conceitos tão bem expostos na parte introdutória. A conclusão ressalta aspectos referentes à conduta feminina e à vivência no noivado e no casamento. Dentre os aspectos levantados, estão: a capacidade feminina em ser pouco exigente diante dos rapazes, o período considerado ideal de noivado, a diferença de idade esperada para ambos, o uso de alianças e o conhecimento do rapaz durante o noivado para que o casamento não venha a ter problemas em razão de defeitos recíprocos, a rotina e o convívio após o matrimônio.

É pertinente notar que o teste traz em seu bojo inúmeros aspectos acerca da sexualidade feminina. As dúvidas da mulher quanto ao noivado e aos desejos sexuais - que parecem ser somente do homem - implicam outras questões que envolvem as condutas ideais para a mulher da época: ser casta, capaz de renunciar não só aos "prazeres da carne" como também às satisfações sociais; saber conviver com o futuro marido, dando-lhe a possibilidade de desfrutar do convívio junto aos amigos; além 
de saber desempenhar capacidades ditas femininas, como cozinhar, consertar roupas... e, sobretudo, caso tenha errado no passado, ser capaz de se penitenciar e se esmerar em ser "digna e respeitável".

O segundo teste, cujos temas são a preparação para o casamento e a conduta desejável para as mulheres, foi publicado na revista Cláudia (n. 64, 1967), com o seguinte título: "Você está pronta para o casamento?". O teste, que não é precedido de texto, traz enunciados pouco comuns. As questões propostas às leitoras são ilustradas por pequenos desenhos. A linguagem das questões sugeridas é sutil, às vezes capciosa:

Você dá tanta importância à elegância de sua lingerie
quanto à de sua roupa? Você leva sempre um
alfinête de fralda na bôlsa? Você evita apertar o
tubo de pasta de dentes pelo meio? Você faz
confidências à sua cabeleireira? Você teria coragem
de usar uma peruca verde? Você é dessas que
gostam de novidades? Se Deus tivesse pedido sua
opinião, você O teria incitado a criar o homem
primeiro? Imagina construir uma vida a dois sôbre
um amor à primeira vista? Se fôsse Noé, você teria
salvo a serpente?

Enfim, são vinte e quatro questões acerca da vivência feminina, com linguagem predominantemente metafórica, além de expressar preceitos religiosos. A conclusão revela conceitos importantes do que se considera ideal de feminilidade para a mulher desse período. A leitora que obtiver, em sua pontuação, a maioria de respostas afirmativas "pode-se considerar madura para o casamento. Não apenas sua personalidade original é uma garantia de bom humor para sua futura vida conjugal, como também suas qualidades de entusiasmo, gentileza e sentido de humor lhe concedem a feminilidade ideal". Em síntese, independentemente do futuro esposo, essa mulher saberá fazê-lo feliz e, também, será considerada a "mais adorável e habilidosa das 'mandonas"'. 
As que responderam medianamente, entre sim e não, são consideradas prontas para o casamento desde que escolham um "homem suficientemente evoluído que possa apreciar suas qualidades profundas". Finalmente, à que respondeu majoritariamente "não":

\begin{abstract}
Honestamente, aconselhamo-la a esperar mais um pouco. Neste momento, o casamento seria para você uma prisão, em vez de um "desabrochar". Seu espírito dominador se coadunaria mal com as concessões inerentes à vida conjugal. A vida precisa ainda dar-lhe alguns tapas antes que você admita depender mais ou menos de um homem. Mas feliz daquele que souber vencer sua resistência, pois você será por muito tempo uma espôsa grata e se revelará a mulher atenta e dedicada que cada um sonha encontrar.
\end{abstract}

Os resultados são taxativos: a mulher que, de acordo com os parâmetros do teste, não esteja preparada para o matrimônio, precisa recolher-se e esperar até que isso venha a se efetivar. É aventada a possibilidade da "solteirice" por algum tempo. No entanto, esse período deverá ser dedicado ao aprendizado do que deve ser a vivência no casamento. Em alguns casos, a estratégia mostra-se rigorosa, prevendo que a própria vida poderá dar "tapas" para que a moça vença as resistências e possa tornar-se a mulher que todo homem sonha encontrar. Os enunciados conclusivos do referido teste admitem novas formas de conduta feminina, como ser solteira por um determinado tempo, mas sem aceitá-las como legítimas, e, sim, como desviantes ou transitórias.

Esse teste também apresenta novos elementos que devem aparecer na "conduta ideal" da mulher que pretende casar-se: a criatividade e o bom humor. Também ressalta que tenha espírito prático e uma pitada de autoridade. São as novas características na constituição da "mulher moderna". Agora, nem muito submissa, nem muito autoritária. Essa "personalidade original" será também capaz de lhe propiciar condições de 
ser educadora das filhas e filhos e, até mesmo, do marido. A feminilidade ideal estimula a mulher a exercer mais uma capacidade, a partir de sua conduta, a de ensinar ao homem. Será tida como exemplo e modelo para o outro, especialmente por seu "entusiasmo, gentileza e bom humor".

A função da dona-de-casa também não poderia passar despercebida por esse gênero da imprensa feminina. Perguntas como "Serei boa dona de casa?” são freqüentes. Exigem-se conhecimentos dos cuidados do lar, dos afazeres domésticos, das habilidades culinárias e de organização. Um curioso teste sobre a temática é intitulado "A manhã de dona Francisca", publicado na revista Capricho (n. 73, 1958). A leitora é solicitada a colocar em ordem cronológica oito desenhos que indicam cenas do cotidiano de dona Francisca. A lida doméstica de uma dona-de-casa, entre seus inúmeros afazeres, e a relação afetiva com o marido são a tônica do referido instrumento. As condutas exigidas da mulher casada indicam os cuidados com o lar e, principalmente, com o bem-estar do esposo. A convivência no casamento parece indicar, mais uma vez, que a mulher deve desempenhar várias ações para garantir a felicidade conjugal; dentre elas, o cuidado constante com a aparência física.

A maternidade é outra função esperada da mulher e privilegiada pelos testes. As questões que orientam a leitora a ser boa mãe não fogem às regras já expostas das demais condutas esperadas da vivência feminina. Os testes sobre a maternidade visam a fazer com que as mães analisem suas condutas diante das/os filhas/os, além de ressaltar a necessidade ou obrigatoriedade da maternidade no casamento. As respostas expressam, justamente, as formas como as mães devem agir diante das crianças. $\mathrm{Na}$ revista Cláudia, a maternidade aparece ligada às temáticas evidenciadas pelas ciências psicológicas e pedagógicas, fazendo emergir o conceito de "mãe moderna". Ela deve preocupar-se com conceitos produzidos por tais disciplinas, que podem indicar a conduta correta de se educar. 


\section{O AUTOCONHECIMENTO PROPOSTO PELOS TESTES}

O autoconhecimento (pessoal e amoroso) também é um dos temas preponderantes nos testes e compõe a segunda categoria a ser descrita. Os testes com esse intuito, apesar de trazerem enunciados muito próximos do que se pretendia acerca da "conduta feminina", descrita anteriormente, é um instrumento para fazer com que a pessoa reflita sobre si própria, como se estivesse diante do espelho, no qual se pudesse visualizar e produzir um discurso sobre o seu próprio "eu".

"Qual destas moças é você" é o título de um teste publicado na revista Capricho (n. 82, 1958), que expressa a idéia dessa categoria, o autoconhecimento e a produção de discurso sobre si propostos pela imprensa analisada. O objetivo é claro desde o questionamento inicial que estimula a leitora a refletir sobre que "espécie" de mulher ela se tornou. Uma pergunta parece inevitável: Com que bases ou parâmetros essa mulher vai se analisar para saber de qual "espécie" se constitui? A função baseada na trindade (esposa-mãe-dona-de-casa) proposta para a vivência feminina tornar-se-ia um dos discursos hegemônicos que poderiam responder ao questionamento. $O$ teste em questão é intitulado de "psicoteste" por suas condições de diagnosticar, analisar as condutas das mulheres, os comportamentos considerados ideais sob a ótica masculina. Esse argumento é relevante como instrumento para que a mulher possa se auto-analisar, ou se autoconhecer, ante o olhar do homem. Tal olhar e determinações masculinas fornecem os roteiros para a leitora se basear no processo de se tornar a "esposa sonhada", a "mãe ideal" e a "filha modelo" e, assim, pertencer a uma "espécie" estipulada pela sociedade como mulher digna e correta. O resultado vem logo no início, antes até das questões, talvez para induzir a mulher a adotar esse modelo de "mulher perfeita" para elaborar reflexões pessoais. As leitoras que responderam afirmativamente a todas as questões - tal indicativo já denota certa obediência às questões propostas - seriam consideradas 
"mulheres modelo". As que respondessem metade das questões de forma afirmativa seriam consideradas "perfeitas", mas com características que precisariam ser corrigidas. Abaixo dessas respostas, o teste, fundamentado no discurso psicológico, indica que "tendes de vos modificar, sob pena de serdes uma verdadeira desilusão para os vossos parentes".

É longa a lista de modelos a serem seguidos, com normas claras de como deve ser a conduta ideal de uma mulher. Todas essas idealizações são acompanhadas de termos que a qualificam; a estratégia é torná-las aceitáveis para orientar a conduta externa e, sobretudo, servir de elemento de reflexão para determinar a própria subjetividade.

Para levar a mulher a se autoconhecer, os testes utilizam inúmeras outras táticas. Dentre elas, a de utilizar o próprio título como elemento de reflexão pessoal, como já evidenciado anteriormente.

Vejam-se alguns exemplos da temática abordada:

Revista Capricho: "Você é tímida?" (n. 1, 1952); "Você sabe amar?” (n. 2, 1952); "Você é uma mulher adaptada?" (n. 21, 1953); "Você ainda é menina?” (n. 24, 1954); "Você entende os outros?” (n. 27, 1954); "Será você intuitiva?” (n. 63, 1957); “Qual o seu tipo de homem?” (n. 73, 1958); “Agrado aos homens, mas... por que se afastam de mim?” (n. 81, 1958); “Qual destas moças é você?” (n. 82, 1958); "Você é sugestionável?” (n. 96, 1960).

Revista Cláudia: "Você é coquete?" (n. 3, 1961); "Você tem autoridade?" (n. 6, 1962); "Você é equilibrada?" (n. 6, 1962); "Você é encantadora?" (n. 11, 1962); "Você é boa amiga?" (n. 12, 1962); "Você é jovem?” (n. 21, 1963); "Você é corajosa?" (n. 22, 1963); "Você é discreta?" (n. 25, 1963); "Você sabe amar?" (n. 25, 1963).

Nessa listagem, é possível verificar como os próprios títulos são reveladores do que esse gênero da imprensa feminina pretendia, ou seja, instigar a reflexão sobre que tipo de mulher seria a leitora. Ou de que "tipo" de mulher a própria leitora poderia se constituir a partir daqueles enunciados apresentados com conceito de verdade. 
Devido à diversidade de temas para a auto-análise e o autoconhecimento, analisar-se-ão alguns testes representativos; em particular, os que propõem uma análise com base nos princípios da feminilidade - publicados especialmente nas décadas de 1950 e 1960. Os testes dos primeiros anos da década de 1970 estimulam a participação efetiva da mulher no lar e no mercado de trabalho, mudando o foco da análise, estritamente pessoal, para a social. Cabe apontarmos algumas mudanças percebidas na revista entre as décadas de 1950 e 1970 em relação ao que se propunha à conduta feminina. Nas décadas de $1950 \mathrm{e}$ 1960, há uma presença marcante de questionamentos em relação à capacidade da mulher de se relacionar socialmente; em particular, com o outro - leia-se homem. Exigia-se que fosse amiga, corajosa, encantadora, agradável, cativante, perfeita, realizada, feliz, jovem e, também, equilibrada, discreta e feminina. Na década de 1970, possivelmente por influência dos discursos feministas, fala-se em mulher emancipada, amiga ou inimiga de outra mulher, durona, ou, simplesmente, a "mulher 1970", que "não tem tempo a perder com idéias antiquadas sôbre submissão feminina. Está preocupada em manter sua posição no mundo dos homens" (Cláudia, n. 118, 1971). Nesses últimos testes, o outro, que serve de referência para a identidade da mulher, é também uma outra, ou seja, alguém do seu próprio gênero ou outras pessoas do universo social mais amplo.

O teste intitulado "Agrado aos homens, mas... por que se afastam de mim?” é representativo da temática de fazer a mulher se auto-analisar a partir do olhar masculino. O teste é precedido por um texto:

Desculpe-nos, amiga. Não nos queremos imiscuir no que não nos interessa, mas você muda de namorados como de sapatos! E está ganhando, entre seus conhecidos, uma pouco invejável fama de namoradeira, de mulher volúvel e "vamp". Certamente, você encolhe os ombros e diz que só 
as pessoas velhas ou antiquadas chamam-na assim, as solteironas ou as invejosas. No entanto, tomamos a liberdade de adverti-la de que não são apenas tais pessoas que fazem êsse juízo de você. " les" também reparam em muita coisa e fazem seus comentários... Claro que não o dizem, nem o demonstram a você. Os homens gostam muito das namoradeiras, mas sentem terror por elas quando pensam nas alianças. (Capricho, n. 81, 1958)

O texto continua com outros enunciados, com os quais condena a conduta da moça que troca de namorado como se colecionasse "amôres como mero esporte". No entanto, a personagem principal, que parece ser a própria leitora, com forte capacidade de sedução, admite que gostaria que seus relacionamentos fossem duráveis e verdadeiros. Mas, segundo o texto, na realidade, "são eles que se afastam após algum tempo e você, em vez de mergulhar num mar de desespêro, dedica-se, sem perda de tempo, a procurar um substituto". A informação sugerida para que esse comportamento feminino não se torne recorrente é a auto-análise, com o seguinte convite: "Antes de iniciar um novo romance, analise-se um pouco”. Essa prática é a estratégia adotada para fazer com que a leitora reflita se está agindo de forma "correta" para ter êxito junto aos homens. O porquê de muitos homens se afastarem dela, apesar de sua capacidade inicial de agradar-lhes, volta a ser a questão. A justificativa é a seguinte: "Todos êles, mesmo os aparentemente mais evoluídos, são um tanto primitivos no fundo. Gostam de dominar, de serem os que 'usam calças', ou pelo menos, querem ter a ilusão de que as usam". Continua afirmando que os homens têm, salvo raríssimas exceções, um grande amor-próprio. A explicação para essa atitude se respalda em sua capacidade natural de sentir necessidade de domínio nas relações amorosas - ou, pelo menos, pensar que as domina - ou na capacidade masculina de sentir um exacerbado amor-próprio que impede de aceitar certas "liberdades" das mulheres. Apesar dessa constatação, o teste levanta a hipótese de que o 
"problema" possa estar na própria conduta feminina. Ora, em vez de apontar o autoritarismo e/ou inabilidade dos homens em lidar com as relações afetivas, prefere insistir na possibilidade de que o "erro" seja da mulher. A partir daí, ela é convidada a responder a doze questões, com resposta afirmativa ou negativa; antes, pede-se-lhe para ser sincera: "Seja, antes de tudo, sincera para consigo mesma, qualidade que, só por si, faz par com a discrição".

As questões são as seguintes:

- Acha-se muito inteligente e o demonstra?

- Gosta de falar até "pelos cotovelos"?

- É exageradamente ciumenta?

- Gosta de chamar a atenção dos outros homens?

- Pinta-se muito, deixando manchas de baton em xícaras, guardanapos e até mesmo no paletó de seu companheiro?

- Gosta de discutir e de dar a "última palavra"?

- No cinema, comenta em voz alta o filme?

- Segue ao pé da letra os ditames da moda, mesmo reconhecendo que às vêzes esta é audaciosa ou pouco elegante?

- Telefona-lhe continuamente, a qualquer hora?

- Costuma contradizê-lo diante dos amigos dêle?

- Porque você vive só para êle, acha que deve corresponder da mesma maneira?

- Trata(-se) de ter bons modos à mesa?

A leitora, por esse processo, precisa conferir aspectos de sua sociabilidade, para com o amado, para se tornar capaz de conquistá-lo. Para tanto, deve observar suas condutas, como: etiqueta à mesa, modos de vestir, altura da voz, comportamento diante dos amigos do namorado, discrição, dentre outras. Deve, também, tornar-se submissa em alguns momentos, de modo a dar-lhe a "última palavra". 
A solução do teste indica o seguinte: Para as que responderam afirmativamente às doze questões, "não tenha dúvidas: a culpa dêles se afastarem é exclusivamente sua". Para as que responderam entre dez e doze "sim", "você é um tanto discreta, mas aconselhamos que se observe e trate de mudar". Para as que tiveram de seis a nove respostas afirmativas, "você poderia ser um pouco mais discreta, não será difícil conseguir isso". Finalmente, para as que responderam afirmativamente de uma a cinco questões, eis o que a autora sentencia: "felicitações a você, amiga, é discretíssima e ninguém pode querer afastar-se de você".

Veja-se que, apesar do tom amistoso da autora para com a leitora, a grande maioria do público feminino deve mudar de conduta. Tais conselhos, no fim dos testes, assumem um caráter imperativo, como se de um lado houvesse alguém que estivesse sendo julgado e, do outro, alguém revestido de poder e saber, julgando a conduta da "ré".

Trazemos, a seguir, mais um teste, "Você é encantadora?", que põe em evidência a relação da leitora diante do ser amado e de outras pessoas. O objetivo é análogo ao do anterior: fazer com que a mulher se analise para poder garantir a continuidade do relacionamento amoroso. O início do teste é o seguinte:

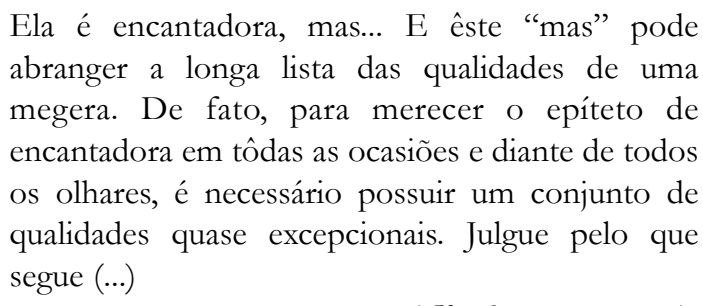

(Cláudia, n. 11, 1962).

A partir daí, o teste ressalta as qualidades exigidas da mulher para ser encantadora: 


\begin{abstract}
Se não fôr bonita e elegante, pelo menos (seja) sempre agradável à vista ("sempre" vigorando desde que se levanta); ser feminina e não feminista; jamais apresentar o menor traço de vulgaridade; ter humor uniforme na escala "amável-sorridenteserena”; possuir tato e intuição; ser alegre e espirituosa com apurado senso de humor; saber perdoar e esquecer; não ser coquete; nunca entrar em desarmonia com pessoa alguma; ser companhia desejável e requisitada tanto pelas mulheres como pelos homens; não permitir que abusem de sua gentileza.
\end{abstract}

Todas as características apontadas, além das descritas anteriormente, o próprio teste ressalta que constituem um conjunto de qualidades "quase excepcionais". É relevante notar que o discurso acerca da vivência feminina aponta vários atributos, ou "conjunto de qualidades", difíceis de transpor na totalidade para a prática cotidiana. O discurso é repleto de enunciados que os tornam impraticáveis. A idéia de imperfeição e falha acompanha a constituição dos sujeitos que estão incessantemente se auto-analisando para atingir a sonhada perfeição. $O$ teste pretende ser um dispositivo capaz de levar a mulher a repensar a sua própria conduta e a se rever tendo por referência essa idealização da feminilidade, que é um produto eminentemente social.

\title{
CONSIDERAÇÕES FINAIS
}

Os testes, como se viu ao longo do texto, por seus enunciados prescritivos e normalizadores, revelaram ser instrumentos pedagógicos com o objetivo de "conduzir as condutas" femininas desde que fossem capazes de instigar o exame e a confissão, tornando o discurso da intimidade mais visível e verbalizado. Observa-se, ainda, que eles indicam conceitos de "verdade", apoiados em códigos morais e, especialmente, em preceitos extraídos de teorias científicas e da moralidade da época a respeito da conduta feminina. $\mathrm{O}$ conceito de verdade está ligado a sistemas de poder que 
o produzem e reforçam. Esses poderes podem ser observados na diversidade de temas ressaltados pelos testes, que apontam para regimes de verdade, não necessariamente negativos ou repressivos, mas fundamentalmente produtivos, porque incitam à reflexão e propiciam possibilidades de trabalho pessoal capaz de produzir novas identidades a partir do que está sendo objetivado social e culturalmente. Então, a leitora ou as mulheres em geral -, ao dizer a verdade sobre si, instigada pelos testes da imprensa feminina, passa a conhecer a si própria e, com isso, comunicase num processo contínuo de constituição de si mesma.

\section{REFERÊNCIAS}

BUITONI, Dulcília H. S. Mulher de papel: a representação da mulher pela imprensa feminina brasileira. São Paulo: Loyola, 1981.

BUITONI, Dulcilia H. S. Imprensa feminina. São Paulo: Ática, 1986.

FOUCAULT, Michel. Vigiar e punir. Petrópolis: Vozes, 1977.

FOUCAULT, Michel. Microfisica do poder. 12. ed. Rio de Janeiro: Graal, 1996.

FOUCAULT, Michel. História da sexualidade: a vontade de saber. 12. ed. Rio de Janeiro: Graal, 1997. v. I.

SANTOS, Jacqueline Rios dos. Minha amiga Claudia: história, gêneros jornalísticos e produção de uma revista feminina. Dissertação (Mestrado) Instituto Metodista de Ensino Superior, Faculdade de Comunicação Social, São Bernardo do Campo, 1996.

XAVIER FILHA, Constantina. Discursos da intimidade: imprensa feminina e narrativas de mulheres-professoras brasileiras e portuguesas na segunda metade do século XX. Tese (Doutorado) - FEUSP, São Paulo, 2005. 


\section{ANEXOS}

\section{Testes da imprensa feminina analisados:}

1. Revista Capricho (Período: 1952 a 1960)

\begin{tabular}{|c|c|c|c|c|}
\hline Número & Ano & Seção & Título & Autoria \\
\hline 01 & 1952 & Psicologia & Você é tímida? & Richard Rest (psicólogo) \\
\hline 02 & 1952 & Psicologia & Você sabe amar? & Richard Rest (psicólogo) \\
\hline 05 & 1952 & Psicologia & Chegou a hora do amor? & Richard Rest (psicólogo) \\
\hline 05 & 1952 & Teste & Casar-me-ei logo? & - \\
\hline 21 & 1953 & Teste & Você é uma mulher adaptada? & - \\
\hline 24 & 1954 & Psicologia & Você ainda é menina? & Pedro Vid \\
\hline 25 & 1954 & Teste & Serei boa dona de casa? & - \\
\hline 25 & 1954 & Psicologia & Sua personalidade e a dêle & Richard Rest \\
\hline 26 & 1954 & Psicologia & Acerte no amor... errando & Lita Dufou (Intérprete \\
\hline & & & & $\begin{array}{l}\text { Delfy Miranda; Claude } \\
\text { Vernet) }\end{array}$ \\
\hline 27 & 1954 & Psicologia & 3 testes - Você entende os outros? & Richard Rest \\
\hline 29 & 1954 & Psicologia & Tal é qual? & Richard Rest \\
\hline 30 & 1954 & Psicologia & Seu noivo é dêste século? & Richard Rest \\
\hline 63 & 1957 & Psicologia & Será você... intuitiva? & Richard Rest \\
\hline 68 & 1957 & Teste & Estou apta para o casamento? & - \\
\hline 72 & 1958 & Psicologia & Conversa de amigo & Walter Forster \\
\hline 73 & 1958 & Teste & A manhã de dona Francisca & - \\
\hline 73 & 1958 & Teste & Qual é o seu tipo de homem? & - \\
\hline 78 & 1958 & Teste & Aprenda a ser livre & Pedro Vid \\
\hline 78 & 1958 & - & $\mathrm{O}$ amor e as côres & Briand Joly \\
\hline 81 & 1958 & Psicologia & $\begin{array}{c}\text { Agrado aos homens, mas... por que } \\
\text { se afastam de mim? }\end{array}$ & Ruth de Vere \\
\hline 82 & 1958 & Psicologia & Exame de consciência & Briand Joly \\
\hline 82 & 1958 & Teste & Qual destas moças é você? & - \\
\hline 84 & 1959 & Psicologia & $\begin{array}{c}\text { Você seria capaz de se casar sem } \\
\text { amor? }\end{array}$ & Briand Joly \\
\hline 85 & 1959 & Psicologia & E, agora, falemos de casamento: & Ruth de Vere \\
\hline & & & qual a idade do amor? & - \\
\hline 96 & 1960 & Teste & Você é sugestionável? & \\
\hline 98 & 1960 & Psicologia & Já que estamos noivos... casemo-nos! & - \\
\hline 99 & 1960 & Teste & Será você uma boa espôsa? & - \\
\hline 100 & 1960 & Teste & Certo ou errado? & - \\
\hline
\end{tabular}


Revista Cláudia (Período: 1961 a 1975)

\begin{tabular}{|c|c|c|c|c|}
\hline Número & Ano & Seção & Título & Autoria \\
\hline 02 & 1961 & Teste & Precisa-se espôsa ciumenta & Dona Letícia \\
\hline 03 & 1961 & Teste relâmpago & Você é coquete? & - \\
\hline 04 & 1962 & Teste & $\begin{array}{l}\text { Qual o primeiro objeto que você } \\
\text { poria num quarto vazio? }\end{array}$ & - \\
\hline 05 & 1962 & Teste & Você é uma companheira ideal? & - \\
\hline 06 & 1962 & Teste relâmpago & Você tem autoridade? & - \\
\hline 06 & 1962 & Cláudia Saúde & Você é equilibrada? & - \\
\hline 06 & 1962 & Teste & Teste dos filósofos & - \\
\hline 07 & 1962 & Teste dos casados & O amor continua? & - \\
\hline 10 & 1962 & Teste & Você é uma mãe moderna? & - \\
\hline 11 & 1962 & Teste & Você é encantadora? & - \\
\hline 12 & 1962 & Teste & Você é uma boa amiga? & - \\
\hline 14 & 1962 & Teste & Você é uma boa mãe? & - \\
\hline 15 & 1962 & Teste & Você é uma boa espôsa? & - \\
\hline 16 & 1963 & Teste & $\begin{array}{l}\text { Teste do casal (ou o desenho do } \\
\text { casamento) }\end{array}$ & - \\
\hline 21 & 1963 & Teste & Você é jovem? & - \\
\hline 21 & 1963 & Teste para a mãe & A educação é uma só & - \\
\hline 22 & 1963 & Teste & Você é corajosa? & - \\
\hline 25 & 1963 & Teste & Você sabe amar? & - \\
\hline 25 & 1963 & Teste & Você é discreta? & - \\
\hline 35 & 1964 & Teste & $\begin{array}{c}\text { O teste perigoso: só para casais } \\
\text { seguros de si }\end{array}$ & - \\
\hline 42 & 1965 & Teste & $\begin{array}{l}\text { Um teste-novidade: Mulher com } \\
\text { mulher se mede }\end{array}$ & - \\
\hline 44 & 1965 & Teste & As quatro faces de EVA & - \\
\hline 45 & 1965 & Teste & O teste da mulher infiel & - \\
\hline 64 & 1967 & Teste de Cláudia & Você está pronta para o casamento? & - \\
\hline 88 & 1969 & O teste de Cláudia & No amor quem é quente e quem é frio? & - \\
\hline 90 & 1969 & O teste de Cláudia & $\begin{array}{l}\text { Como vocês reagem às pequenas } \\
\text { dificuldades conjugais? }\end{array}$ & - \\
\hline 91 & 1969 & Teste & Um teste para solteiras & - \\
\hline 113 & 1971 & O teste de Cláudia & Seu rosto mostra quem você é & - \\
\hline 114 & 1971 & O teste de Cláudia & Em que você pensa ao olhar esta foto? & - \\
\hline 118 & 1971 & O teste de Cláudia & $\begin{array}{c}\text { Você tem coagem de fazer o nosso } \\
\text { teste? }\end{array}$ & - \\
\hline 203 & 1978 & Teste & Você é uma dona de casa feliz? & - \\
\hline
\end{tabular}


Recebimento: 12/06/2007

Aprovação: 14/09/2007

\section{Contato:}

Rua Cidade Universitária, s/ $\mathrm{n}^{\circ}$

Universitário - Campo Grande

Cep: 79070-900 - Mato Grosso do Sul - Brasil

tinaxav@gmail.com 